\title{
CÁC YẾU TỐ ẢNH HƯởNG ĐẾN SỰ HÀI LÒNG CỦA DU KHÁCH NộI ĐỊA ĐỐI VỚI ĐIỂM ĐẾN THÀNH PHỐ HỒ CHÍ MINH SAU ĐợT MỘT ĐẠI DỊCH COVID-19
}

\author{
PHẠM XUÂN GIANG ${ }^{1}$, HUỲNH NGUYỄN BẢO NGỌC ${ }^{2}$ \\ ${ }^{1}$ Truoòng Đại học Công nghiệp Thành phố Hồ Chí Minh, \\ ${ }^{2}$ Công ty TNHH Esuhai \\ phamxuangiang@iuh.edu.vn
}

Tóm tắt. Nghiên cứu sự hài lòng của du khách đối với điểm đến là một chủ đề không mới. Tuy vậy, nghiên cứu sau đợt một đại dịch COVID-19 là một nghiên cứu mới và cấp thiết cho thành phố Hồ Chí Minh. Kế thừa kết quả của những nghiên cứu đi trước, nghiên cứu này đã bổ sung 02 biến quan sát mới để đo lường sự hài lòng của du khách trong bối cảnh có đại dịch COVID-19. Với cỡ mẫu 393 du khách, nghiên cứu đã xác định được 05 yếu tố thực sự có ảnh hưởng đến sự hài lòng của du khách nội địa. Đó là An toàn điểm đến có mức độ ảnh hưởng lớn nhất, tiếp theo là Tài nguyên du lịch và điều kiện vật chất, Môi trường, $\mathrm{Co}$ sở lưu trú và cuối cùng có ảnh hưởng yếu nhất là yếu tố Dịch vụ ăn uống, giải trí, mua sắm. Từ đó, 05 khuyến nghị tăng cường sự hài lòng của du khách nội địa đã được đề xuất nhằm phát triển du lịch thành phố trong điều kiện có dịch.

Từ khóa: Sự hài lòng, Du khách nội địa, COVID-19, Đợt một đại dịch, Điểm đến TP.HCM.

\section{FACTORS AFFECTING THE SATISFACTION OF DOMESTIC VISITORS AT HO CHI MINH CITY DESTINATION IN COVID-19 PANDEMIC}

\begin{abstract}
Research on the satisfaction of visitors to a destination is not a new topic. However, the study in the context of COVID-19 pandemic is a new and necessary to Ho Chi Minh City. Based on the results of previous studies, this study added two new items which were scaled the factor of visitors' satisfaction in the context of the COVID-19 pandemic. With sample size of 393 visitors, the study has identified 05 factors that really affect the satisfaction of domestic tourists. It is Safety Destination with the greatest impact, followed respectively by Travel Resources and Physical Conditions, Environment, Accommodation and ultimately Food Service, Entertainment, Shopping. Since then, 05 recommendations to enhance the domestic tourist satisfaction have been proposed to develop the City tourism in epidemic conditions.
\end{abstract}

Keywords: Satisfaction, Domestic tourists, COVID-19, Pandemic, HCMC Destination.

\section{MỞ ĐÀ̀U}

Nghiên cứu sự hài lòng của du khách đối với điểm đến là một chủ đề không mới và đã từng có nhiều nghiên cứu. Ngoài nước có nghiên cứu của Tribe và Snaith (1998), của Bindu Narayan và cộng sự (2008), Shahrivar (2012), Jayasinghe và cộng sự (2015),... Trong nước có nghiên cứu của Vũ Thị Cẩm Nga (2014), Đặng Thị Thanh Loan (2015), Đinh Kiệm và Nguyễn Đình Bình (2019), Nguyễn Công Viện (2020), ... Các nghiên cứu này đã tìm ra những yếu tố thực sự có ảnh hưởng đến sự hài lòng của du khách. Tuy nhiên, đại dịch COVID-19 đã nhanh chóng gây ảnh hưởng nặng nề cho du lịch thế giới nói chung và Việt Nam nói riêng. Báo cáo của UNWTO cho hay, lượng khách du lịch quốc tế trong năm 2020 sụt giảm tới 1,1 tỷ lượt, tổng thu du lịch toàn cầu mất 1,1 nghìn tỷ USD, khoảng 100-120 triệu lao động trong ngành bị mất việc làm. Theo Tổng cục trưởng Tổng cục Du lịch Việt Nam, ông Nguyễn Trùng Khánh, thì "đại dịch COVID19 đã gây ảnh hưởng nặng nề cho ngành du lịch của nước ta".

Thế nhưng tại Việt Nam, sau bùng phát đợt 1, COVID-19 tạm lắng, kéo theo sự trở lại của du khách nội địa đến với các điểm du lịch, trong đó có thành phố Hồ Chí Minh (TP.HCM). Sự an toàn cùng với thông tin về trình độ $\mathrm{y}$ tế và khả năng hỗ trợ sức khỏe sẽ là một trong những yếu tố quan trọng ảnh hưởng đến sự hài lòng của du khách trong bối cảnh mới. Chính vì vậy, nghiên cứu sự hài lòng của du khách đối với các 
điểm đến tại nước ta nói chung, TP.HCM nói riêng sau đợt một đại dịch COVID-19 là cần thiết. Đây là một nghiên cứu trong bối cảnh mới với mục tiêu đề xuất được một số hàm ý nhằm làm tăng sự hài lòng của du khách nội địa trong điều kiện có dịch, để làm sao du lịch của thành phố vẫn phát triển mà du khách vẫn được an toàn.

Đối tượng khảo sát là du khách nội địa đến du lịch TP.HCM từ tháng 6-7/2020 với phương pháp khảo sát trực tuyến bằng cách liên hệ với công ty du lịch, đại lý lữ hành hoặc khách sạn tại TP.HCM để xin thông tin liên lạc của du khách. Sau đó, nhóm tác giả liên hệ trực tiếp với du khách thông qua điện thoại hoặc email. Nếu họ đồng ý trả lời thì phiếu khảo sát soạn thảo bằng phần mềm google drive sẽ được gửi đi, ngược lại thì chuyển sang du khách khác.

\section{CƠ SỞ LÝ THUYẾT VÀ MÔ HÌNH NGHIÊN CÚU}

\subsection{Cơ sở lý thuyết}

Điểm đến du lịch là địa điểm mà du khách lựa chọn trong chuyến đi, đó có thể là một địa danh cụ thể, một khu vực, một vùng lãnh thổ, một quốc gia, thậm chí là một châu lục. Điểm đến có thể ở ngoài (gọi là du lịch quốc tế) hoặc ở trong lãnh thổ quốc gia của du khách (gọi là du lịch nội địa).

Theo giáo trình “Tổng quan về du lịch" của Vũ Đức Minh (2008), điểm đến du lịch bao gồm các yếu tố: Các điểm hấp dẫn du lịch, giao thông đi lại, nơi ăn nghỉ, các tiện nghi và dịch vụ hỗ trợ, các hoạt động bổ sung. Sự hài lòng của du khách đối với điểm đến là sự hài lòng của họ về những yếu tố này. Đó chính là kết quả của sự tương tác giữa giá trị cảm nhận và mong đợi của du khách về điểm đến. Nói theo Pizam Neumann và Reichel (1978), thì "sự hài lòng của du khách là kết quả so sánh giữa trải nghiệm của du khách tại các điểm du lịch đã đến với những kỳ vọng của họ về những điểm đến”. Nếu kết quả so sánh là dương thì du khách sẽ hài lòng, họ rất có thể sẽ trở lại điểm đến. Ngược lại, sẽ không hài lòng và như vậy, ít có khả năng họ sẽ trở lại điềm đến.

Theo điều 10 của Luật Du lịch (2017) thì "Khách du lịch bao gồm khách du lịch nội địa, khách du lịch quốc tế đến Việt Nam và khách du lịch ra nước ngoài". Trong đó "Khách du lịch nội địa là công dân Việt Nam, người nước ngoài cư trú ở Việt Nam đi du lịch trong lãnh thổ Việt Nam". Họ có đặc điểm khác với du khách quốc tế là chú trọng hơn việc khám phá sự đa dạng, điểm đến tham quan gần hơn, chi phí của chuyến đi tốn kém ít hơn và thời gian lưu trú thường dài hơn, do họ không bị ràng buộc về ngôn ngữ, visa, hộ chiếu,...Những đặc điểm trên đây chi phối đến việc lựa chọn các yếu tố thuộc mồ hình nghiên cứu sự hài lòng của du khách nội địa.

Các lý thuyết và nhiều công trình nghiên cứu của những nhà kinh tế tiền bối, như: Maslow (1943), Oliver (1980), Parasuraman và cộng sự (1988), Zeithaml (1988), Bitner và Hubbert (1994), Spreng và cộng sự (1996), Zeithaml and Bitner (2000), Philip Kotler (2001),... là lý thuyết nền của các nghiên cứu về sự hài lòng khách hàng nói chung và du khách nói riêng. Theo đó, một số nghiên cứu ngoài nước và trong nước có trước, bao gồm:

"Mô hình các nhân tố ảnh hưởng đến sự hài lòng của du khách đối với một điểm đến" của Tribe và Snaith (1998). Nghiên cứu đã cho thấy, sự hài lòng của du khách trong kỳ nghỉ đối với điểm đến Varadero (Cuba) chịu ảnh hưởng 06 yếu tố là (1)tài nguyên du lịch và điều kiện vật chất, (2)môi trường, (3)di sản văn hóa, (4)cơ sở lưu trú, (5)dịch vụ ăn uống, giải trí, mua sắm và (6)dịch vụ chuyển tiền.

Năm 2008, nghiên cứu của Bindu Narayan và cộng sự về "Các yếu tố ảnh hưởng đến sự hài lòng của khách du lịch bang Kerela, Ấn Độ" đã đề nghị hai mô hình nghiên cứu. Kết quả cho thấy, mô hình thứ nhất có độ phù hợp cao hơn so với mô hình thứ hai. Theo đó, 05 yếu tố độc lập có ảnh hưởng đến sự hài lòng của du khách trong mô hình thứ nhất bao gồm: (1)lòng mến khách, (2)thực phẩm, (3)hậu cần - sự chu đáo, (4)an ninh và (5)giá trị tương xứng với tiền khách bỏ ra.

Đến năm 2012, trong "Mô hình các nhân tố ảnh hưởng đến sự hài lòng của du khách ở Malaysia", Shahrivar đã tìm ra 08 yếu tố có ảnh hưởng đến sự hài lòng điểm đến. Đó là: (1)điều kiện tự nhiên, (2)di sản văn hóa, (3)dịch vụ tham quan, mua sắm, (4)khả năng tiếp cận điểm đến, (5)cơ sở hạ tầng, (6)sự đón tiếp, (7)an ninh/an toàn và cuối cùng $(8)$ giá/chi phí .

Năm 2015, trong "Mô hình các nhân tố ảnh hưởng đến sự hài lòng của du khách ở Nuwara Eliya, Sri Lanka" Jayasinghe, Gnanapala và Sandaruwani đã chỉ ra 9 nhân tố là (1)cơ sở lưu trú, (2)dịch vụ ăn uống, (3)dịch vụ hướng dẫn, (4)khí hậu, (5)điểm tham quan, (6)giá, (7)người dân và nhân viên phục vụ, (8) các dịch vụ 
và (9) cơ sở hạ tầng thực sự có ảnh hưởng đến sự hài lòng của du khách đối với điểm đến du lịch Nuwara Eliya.

Vũ Thị Cẩm Nga (2014) trong "Mô hình các nhân tố ảnh hưởng đến sự hài lòng của khách du lịch nội địa đối với du lịch văn hóa Thành phố Cần Tho" lại tìm ra 6 yếu tố có ảnh hưởng đến sự hài lòng, đó là: (1)môi trường, (2)tài nguyên du lịch và điều kiện vật chất, (3)di sản văn hóa, (4)cơ sở lưu trú, (5)dịch vụ ăn uống, giải trí, mua sắm và (6)dịch vụ đổi, chuyển tiền.

Năm 2015, Đặng Thị Thanh Loan trong "Mô hình các nhân tố ảnh hưởng đến sự hài lòng của khách du lịch đối với điểm đển Bình Định" đã xác định được 08 yếu tố có ảnh hưởng đến sự hài lòng của du khách là (1)tài nguyên du lịch, (2)giá, (3)hướng dẫn viên, (4)văn hóa, lịch sử và nghệ thuật, (5)dịch vụ ăn uống, mua sắm và giải trí, (6)môi trường du lịch, (7)cơ sở hạ tầng và (8)khả năng tiếp cận.

Vào năm 2019, Đinh Kiệm và Nguyễn Đình Bình trong "Ứng dụng mô hình HOLSAT đánh giá sự hài lòng của khách du lịch nội địa tại điểm đến thành phố Bảo Lộc" đã chỉ ra 6 nhóm yếu tố có ảnh hưởng đến sự hài lòng, là (1)môi trường, (2)điều kiện tự nhiên, (3)di sản văn hóa, (4)giá cả, (5)cơ sở lưu trú, tham quan giải trí và (6) giao thông.

Còn Nguyễn Công Viện (2020) với "Mô hình nghiên cứu các yếu tố ảnh hưởng đến sự hài lòng của khách du lịch cộng đồng vùng Tây Bắc" đã xác định được 5 yếu tố là (1)văn hóa bản địa, (2)môi trường tham quan, (3)tính hấp dẫn của tự nhiên, (4)cơ sở hạ tầng và (5)giá cả dịch vụ tại điểm du lịch có ảnh hưởng đến sự hài lòng của du khách.

Với 18 yếu tố được tổng hợp lại từ các nghiên cứu trên đây, căn cứ vào đặc điểm của du khách nội địa, nhóm tác giả dự kiến chọn 06 yếu tố, là: (1)Tài nguyên du lịch và điều kiện vật chất; (2) Môi trường; (3)Di sản văn hóa; (4) Cơ sở lưu trú; (5) Dịch vụ ăn uống, giải trí, mua sắm và (6)Án toàn điểm đến để đưa vào mô hình nghiên cứu sự hài lòng.

Biến quan sát dùng để đo lường các yếu tố của mô hình được biên dịch từ các nghiên cứu tham khảo trên đây. Tuy nhiên, để đánh giá đúng sự hài lòng của du khách trong điều kiện COVID-19 vẫn chưa được kiểm soát hoàn toàn, hai biến quan sát là (i)Điểm đến TP.HCM luôn lưu ý du khách về đề phòng COVID-19 và (ii)Điểm đến TP.HCM có các phương tiện phòng chống COVID-19 cho du khách sẽ được bổ sung vào yếu tố An toàn điểm đến.

\subsection{Giả thuyết và mô hình nghiên cứu}

\subsubsection{Giả thuyết nghiên cưu}

Tài nguyên du lịch và điều kiện vật chất

Theo điều 3 của Luật Du lịch (2017), thì "Tài nguyên du lịch là cảnh quan thiên nhiên, yếu tố tự nhiên và các giá trị văn hóa làm cơ sở để hình thành sản phẩm du lịch, khu du lịch, điểm du lịch, nhằm đáp ứng nhu cầu du lịch. Tài nguyên du lịch bao gồm tài nguyên du lịch tự nhiên và tài nguyên du lịch văn hóa".

Điều kiện vật chất trong du lịch là tình trạng về phương tiện vật chất được huy động tham gia vào việc khai thác các tài nguyên du lịch nhằm tạo ra và thực hiện các dịch vụ du lịch trong chuyến hành trình. Điều kiện vật chất trong du lịch bao gồm khách sạn, nhà hàng, khu vui chơi giải trí, phương tiện vận chuyển,...

Nghiên cứu của Tribe và Snaith (1998), Shahrivar (2012), Nguyễn Vương (2012), Võ Thị Cẩm Nga (2014) và của Đặng Thị Thanh Loan (2015) đã chỉ ra tài nguyên du lịch và điều kiện vật chất có tác động mạnh đến sự hài lòng của du khách đối với điểm đến. Vì vậy:

Giả thuyết H1: Tài nguyên du lịch và điều kiện vật chất có ảnh hưởng tích cực đến sụ hài lòng của du khách nội địa đối với điểm đến TP.HCM sau đợt một đại dịch COVID-19

Môi trường

Trong báo cáo chuyên đề về "Bảo vệ môi trường du lịch" của Phạm Trung (2010) thì môi trường du lịch được hiểu là "các nhân tố về tự nhiên, kinh tế - xã hội và nhân văn trong đó hoạt động du lịch tồn tại và phát triển". Nghiên cứu của Tribe và Snaith (1998), của Bindu Narayan và cộng sự (2008), của Ái Cẩm (2011), của Võ Thị Cẩm Nga (2014), của Đinh Kiệm và Nguyễn Đình Bình (2019) và của Nguyễn Công Viện (2020) cũng đã cho thấy, môi trường du lịch tạo ra được sự thu hút, gây thiện cảm và từ đó ảnh hưởng đến sự hài lòng của du khách đối với điểm đến. Vì vậy:

Giả thuyết H2: Môi truờng có ảnh hưởng tích cực đến sụ hài lòng của du khách nội địa đối với điểm đến TP.HCM sau đọt một đại dịch COVID-19 
Di sản văn hóa

Theo điều 1 của Luật Di sản Văn hóa (2001) thì "Di sản văn hoá quy định tại Luật này bao gồm di sản văn hoá phi vật thể và di sản văn hoá vật thể, là sản phẩm tinh thần, vật chất có giá trị lịch sử, văn hoá, khoa học, được lưu truyền từ thế hệ này qua thế hệ khác ở nước Cộng hoà xã hội chủ nghĩa Việt Nam"

Di sản văn hóa là một trong những yếu tố có ảnh hưởng đến việc lựa chọn điểm đến của du khách. Nghiên cứu của Tribe và Snaith (1998), Shahrivar (2012), Võ Thị Cẩm Nga (2014), Đặng Thị Thanh Loan (2015), của Jayasinghe, Gnanapala và Sandaruwani (2015), của Đinh Kiệm và Nguyễn Đình Bình (2019) đã chứng mình được rằng, yếu tố di sản văn hóa có ảnh hưởng đến sự hài lòng của du khách đối với điểm đến. Vì vậy:

Giả thuyết H3: Di sản văn hóa có ảnh huơong tích cực đến sụ hài lòng của du khách nội địa đối với điểm đến TP.HCM sau đợt một đại dịch COVID-19

Cơ sở lưu trú

Theo Tổng cục Du lịch (2017), cơ sở lưu trú du lịch là cơ sở cho thuê buồng, giường và cung cấp các dịch vụ khác phục vụ khách lưu trú, trong đó khách sạn là cơ sở lưu trú du lịch chủ yếu. Ngoài ra, cơ sở lưu trú còn có: làng du lịch, biệt thự du lịch, căn hộ du lịch, bãi cắm trại du lịch, nhà nghỉ du lịch, nhà ở có phòng cho khách du lịch thuê và các cơ sở lưu trú du lịch khác.

Cơ sở lưu trú càng có chất lượng thì sự hài lòng của du khách đối với điểm đến càng cao. Điều đó cũng được thể hiện trong các nghiên cứu cứu của Tribe và Snaith (1998), của Võ Thị Cẩm Nga (2014). Vì vậy:

Giả thuyết H4: Cơ sở luu trú có ảnh hưởng tích cực đến sụ hài lòng của du khách nội địa đối với điểm đến TP.HCM sau đợt một đại dịch COVID-19

Dịch vụ ăn uống, giải trí, mua sắm

Đối với khách du lịch, dịch vụ ăn uống, tham quan, giải trí là điều tất yếu và quan trọng. Theo thuyết nhu cầu của Maslow (1943), dịch vụ này thuộc nhu cầu sinh lý, bao gồm những nhu cầu cơ bản và thiết yếu để tồn tại như ăn, ngủ, giải trí...Chính vì vậy, đây là yếu tố đầu tiên, quan trọng ảnh hưởng đến sự hài lòng của du khách. Nghiên cứu của Tribe và Snaith (1998), của Võ Thị Cẩm Nga (2014),... cũng đã tìm ra sự ảnh hưởng của nhân tố này đến sự hài lòng của khách du lịch. Vì vậy:

Giả thuyết H5: Dịch vu ăn uống, giải trí, mua sắm có ảnh hưởng tích cục đến sụ hài lòng của du khách nội địa đối với điểm đến TP.HCM sau đợt một đại dịch COVID-19

An toàn điểm đến

An toàn điểm đến chính là sự yên ổn, không có tai họa tại điểm du lịch. Tại TP.HCM, an toàn điểm đến cũng chính là an toàn về tài sản, tính mạng của du khách, không còn nạn cướp giật, chèo kéo và tại thời điểm này - rất quan trọng - đó là phải an toàn COVID. Trong tháp nhu cầu của Maslow (1943), đây là loại nhu cầu thiết yếu thứ hai của con người, sau nhu cầu sinh lý. Và do đó, an toàn của điểm đến ảnh hưởng rất lớn đến sự hài lòng của du khách. Nghiên cứu của Bindu Narayan và cộng sự (2008), của Shahrivar (2012),...đã chứng tỏ điều đó. Vì vậy:

Giả thuyết H6: An toàn điểm đến có ảnh hưởng tích cực đến sự hài lòng của du khách nội địa đối với điểm đến TP.HCM sau đợt một đại dịch COVID-19

Các biến kiểm soát: giới tính, độ tuổi, trình độ học vấn và số lần đến du lịch TP.HCM của du khách cũng được dự kiến đưa vào mô hình nghiên cứu, với mong muốn kiểm định các nhóm du khách trong từng tiêu chí có khác nhau hay không về sự hài lòng.

\subsubsection{Mô hình nghiên cứu}

Biện luận ở trên cho thấy, sự hài lòng của du khách nội địa có mối liên hệ với 06 yếu tố độc lập đã được dự kiến đưa vào mô hình nghiên cứu, vì vậy: 


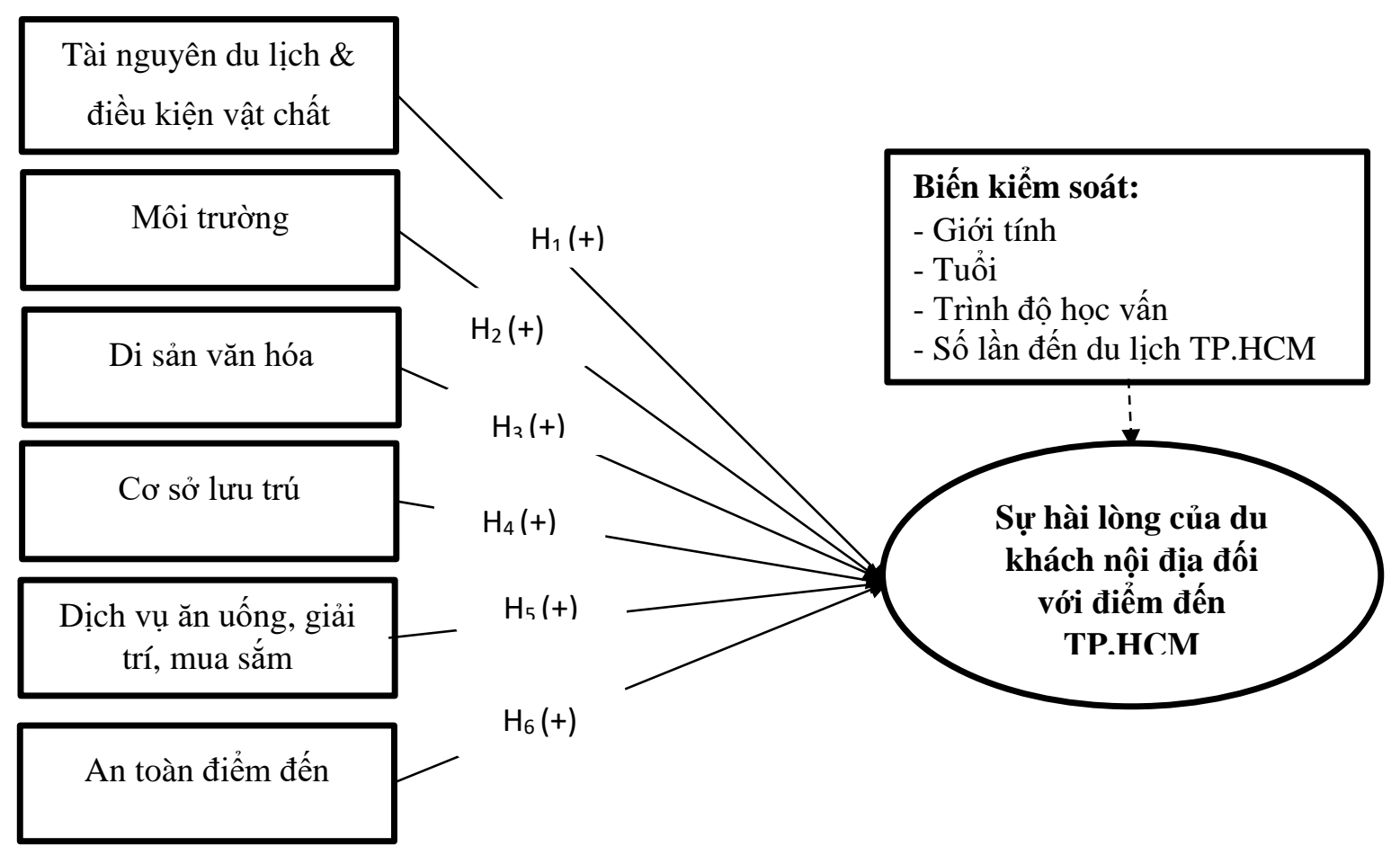

Hình 1. Mô hình nghiên cứu đề xuất

\section{PHƯƠNG PHÁP NGHIÊN CÚU}

Nghiên cứu sử dụng hỗn hợp hai phương pháp là định tính và định lượng. Nghiên cứu định tính được thực hiện qua hai vòng thảo luận với 06 chuyên gia am hiểu về lĩnh vực du lịch.

Vòng 1: Thảo luận các yếu tố có trong mô hình nghiên cứu chính thức

Vòng 2: Thảo luận các biến quan sát dùng đo lường các yếu tố

Nghiên cứu định lượng với công cụ là phần mềm SPSS 24 được tiến hành qua hai bước:

Bước 1: Nghiên cứu định lượng sơ bộ

Kết quả của bước nghiên cứu này là cơ sở để đánh giá sơ bộ thang đo và biến quan sát bằng kiểm định Cronbach's Alpha, đồng thời là bước hiệu chỉnh phiếu khảo sát thông qua sự phản hồi của những người được điều tra. Kích thước mẫu của nghiên cứu sơ bộ là 30 du khách được lấy theo phương pháp thuận tiện.

Bước 2: Nghiên cứu định lượng chính thức

Kết quả của bước nghiên cứu này là dùng để đánh giá độ phù hợp của mô hình và mức độ ảnh hưởng của từng yếu tố độc lập đến yếu tố phụ thuộc. Công cụ thu thập dữ liệu là phiếu khảo sát 5 mức độ theo thang đo Likert với kích thước mẫu là 393 du khách. Kích thước này được xác định theo Comrey và Lee (1992) "mẫu 100 được coi là tệ, 200 được coi là khá, 300 được coi là tốt, 500 được coi là rất tốt và $>=1000$ được coi là tuyệt vời".

\section{KẾT QUẢ NGHIÊN CÚUU VÀ THẢO LUẬN}

\subsection{Kết quả nghiên cứu định tính}

Trong nghiên cứu định tính vòng 1 , các chuyên gia đồng ý giữ nguyên 06 yếu tố độc lập có trong mô hình, vì vậy mô hình nghiên cứu đề xuất cũng chính là mô hình nghiên cứu chính thức. Thảo luận vòng 2 về biến quan sát dùng đo lường 06 yếu tố độc lập và 01 yếu tố phụ thuộc của mô hình, các chuyên gia đồng ý với 02 biến do nhóm tác giả mới bổ sung vào yếu tố An toàn điểm đến. Trong khi đó, 32 biến còn lại (biên dịch từ các nghiên cứu có trước) được đề nghị loại 04 biến (vì có sự trùng lắp về nội dung hoặc không phù hợp với điểm đến TP.HCM). Và do đó, số biến quan sát của mô hình nghiên cứu chính thức còn lại là 30 , thay vì 34 như dự thảo ban đầu. 
Tên các biến, cách mã hóa thang đo và nguồn kế thừa được thể hiện trong bảng 1 (phụ lục)

\subsection{Kết quả nghiên cứu định lượng sơ bộ}

Kết quả nghiên cứu định lượng sơ bộ cho thấy, hai biến MT5 và AGM1 bị loại vì có hệ số tương quan biến tổng <0,3 (lần lượt là 0,019 và 0,158 ). Kiểm định lại, 06 yếu tố độc lập có hệ số Cronbach's Alpha từ 0,715 đến 0,904 thỏa điều kiện lớn hơn 0,6 và hệ số tương quan biến tổng của 28 biến quan sát còn lại giao động từ 0,356 đến 0,865 thỏa điều kiện lớn hơn 0,3 . Như vậy, tất cả chúng đủ điều kiện để tiến hành bước nghiên cứu chính thức

\subsection{Kết quả nghiên cứu định lượng chính thức}

Mẫu và cơ cấu mẫu trong nghiên cứu định lương chính thức

Thời gian khảo sát chính thức từ 15/6/2020 đến 30/7/2020 qua google drive. Phiếu khảo sát được gửi qua Zalo, email, facebook cho 450 du khách nội địa, thu về 404 phiếu, có 393 phiếu hợp lệ (chiếm 97,28\%). Cơ cấu mẫu được xác định theo bốn tiêu chí là độ tuổi, giới tính, trình độ học vấn và số lần đi du lịch tại điểm đến TP.HCM. Theo đó, chiếm tỷ trọng cao nhất là du khách có độ tuồi từ 22-32 tuổi với 146 người bằng 37,1\%; giới tính nữ có 236 người chiếm 60,1\%; trình độ trung cấp và cao đẳng có 103 người chiếm 26,3\% và đến du lịch TP.HCM lần đầu có 330 người chiếm $84,0 \%$.

\section{Kiểm định Cronbach's Alpha}

Kết quả kiểm định Cronbach's Alpha được thể hiện trong bảng 2 (phụ lục). Theo đó, cả 06 yếu tố độc lập và 01 yếu tố phụ thuộc của mô hình đều có hệ số Cronbach's Alpha từ 0,730 đến 0,845 , thỏa điều kiện Cronbach's Alpha lớn hơn 0,6 và hệ số tương quan biến tổng từ 0,491 đến 0,828 thỏa điều kiện lớn hơn 0,3 . Như vậy, sau bước kiểm định này, mô hình vần giữ nguyên 07 yếu tố với 28 biến quan sát.

Phân tích nhân tố khám phá (EFA)

Phân tích EFA cho các yếu tố độc lập có kết quả trong bảng 3 (phụ lục). Theo đó, 06 yếu tố độc lập có hệ số $\mathrm{KMO}=0,870>0,5$; giá trị Sig. (Bartlett's test) $=0,000<0,05 ; 25$ biến quan sát đưa vào phân tích đều có hệ số tải nhân tố lớn hơn 0,5 và tại giá trị Eigenvalues $=1,056>1$ của phương pháp trích Principal Components với phép xoay Varimax đã rút trích được 06 yếu tố, tổng phương sai trích bằng 63,192\% > $50 \%$, chứng tỏ 63,192\% biến thiên của tập dữ liệu được giải thích bởi 06 yếu tố.

Phân tích EFA cho yếu tố phụ thuộc "Sự hài lòng" với 03 biến quan sát là SHL1, SHL2, SHL3 được kết quả trong bảng 4 (phụ lục). Theo đó, yếu tố phụ thuộc có hệ số $\mathrm{KMO}=0,723>0,5$; giá trị Sig. (Bartlett's test $)=0,000<0,05 ; 03$ biến quan sát đưa vào phân tích đều có hệ số tải nhân tố lớn hơn 0,5 và tại giá trị Eigenvalues $=2,297>1$ của phương pháp trích Principal Components đã rút trích được 01 yếu tố, tổng phương sai trích bằng 76,599\% > 50\%, chứng tỏ 76,599\% biến thiên của tập dữ liệu được giải thích bởi 01 yếu tố.

\section{Phân tích hồi quy bội}

Trong phân tích tương quan Pearson, cả 06 biến độc lập đều có tương quan khá chặt chẽ với biến phụ thuộc ở mức ý nghĩa $1 \%$, mạnh nhất là biến ATDD rồi đến TNDK, MT, AGM, CSLT và cuối cùng là biến DSVH với hệ số tương quan bằng $23,1 \%$. Kết quả có trong bảng sau:

Bảng 5. Kiểm định hệ số tương quan Pearson

\begin{tabular}{|ll|l|l|l|l|l|l|l|}
\hline & TNDK & MT & DSVH & CSLT & AGM & ATDD & SHL \\
\hline SHL & Pearson Correlation &, $497^{* *}$ &, $487^{* *}$ &, $231^{* *}$ &, $395^{* *}$ &, $462^{* *}$ &, $730^{* *}$ & 1 \\
& Sig. (2-tailed) &, 000 &, 000 &, 000 &, 000 &, 000 &, 000 & \\
N & 393 & 393 & 393 & 393 & 393 & 393 & 393 \\
\hline
\end{tabular}

** Correlation is significant at the 0,01 level (2-tailed),

Nguồn: Kết quả phân tích SPSS

Kết quả hồi quy bội lần 1 được kết quả trong bảng 6 (phụ lục). Theo đó, biến Di sản văn hóa (DSVH) có giá trị Sig.= 0,633>0,05 nên bị loại khỏi mô hình.

Tiến hành phân tích hồi quy bội lần hai có kết quả trong bảng dưới đây:

Bảng 7. Kết quả phân tích hồi quy lần 2 

ĐIỂM ĐẾN THÀNH PHỐ HỒ CHÍ MINH SAU ĐỢT MỘT ĐẠI DỊCH COVID-19

\begin{tabular}{|c|c|c|c|c|c|c|c|c|}
\hline \multirow{2}{*}{\multicolumn{2}{|c|}{ Mô hình }} & \multicolumn{2}{|c|}{ Hệ số không chuẩn hóa } & \multirow{2}{*}{$\begin{array}{l}\text { Hệ số chuẩn hóa } \\
\text { Beta }\end{array}$} & \multirow[b]{2}{*}{$\mathrm{t}$} & \multirow[b]{2}{*}{ Sig. } & \multicolumn{2}{|c|}{ Thống kê Collinearity } \\
\hline & & \multirow{2}{*}{$\begin{array}{l}\text { B } \\
-1,411\end{array}$} & \multirow{2}{*}{$\begin{array}{l}\text { Std. Error } \\
, 385\end{array}$} & & & & \multirow{2}{*}{ Tolerance } & \multirow[t]{2}{*}{ VIF } \\
\hline \multirow[t]{6}{*}{1} & (Constant) & & & & $-3,668$ & ,000 & & \\
\hline & TNDK & , 176 & ,052 & ,142 & 3,417 & ,001 & ,638 & 1,566 \\
\hline & MT & , 177 & 062 &, 129 & 2,843 & 005 & ,537 & 1,863 \\
\hline & CSLT & , 149 & 055 &, 125 & 2,727 & 007 &, 524 & 1,910 \\
\hline & AGM &, 125 & 050 & , 106 & 2,491 & 013 & 611 & 1,636 \\
\hline & ATDD & ,749 & 054 & 605 & 13,831 & 000 &, 575 & 1,739 \\
\hline \multicolumn{9}{|c|}{ Biến phụ thuộc: Sự hài lòng } \\
\hline \multicolumn{3}{|c|}{$\mathrm{R}=0,758$} & \multicolumn{3}{|l|}{$\mathrm{R}^{2}=0,574$} & \multicolumn{3}{|c|}{$\mathrm{R}^{2}$ hiệu chỉnh = 0,568 } \\
\hline \multicolumn{3}{|c|}{ Durbin-Watson $=1,906$} & \multicolumn{3}{|c|}{$\mathrm{F}=104,442$} & \multicolumn{3}{|c|}{ Sig. $=0,000$} \\
\hline
\end{tabular}

Nguồn: Kết quả phân tích SPSS

Bảng trên có $\mathrm{R}^{2}$ hiệu chỉnh bằng 0,568 chứng tỏ độ phù hợp của mô hình là $56,8 \%$. Hay nói cách khác là $56,8 \%$ sự biến thiên của biến sự hài lòng được giải thích bởi 05 biến độc lập còn lại. Ngoài ra, kết quả phân tích độ phù hợp của mô hình thông qua kiểm định ANOVA được giá trị thống kê $\mathrm{F}=104,442$ và Sig. < 0,05 đã khẳng định mô hình hồi quy là phù hợp với tập dữ liệu, vì vậy các biến độc lập đều đạt tiêu chuẩn. Phương trình hồi quy chuẩn hóa như sau:

SHL $=(0,605 *$ ATDD $)+(0,142 *$ TNDK $)+(0,129 *$ MT $)+(0,125 *$ CSLT $)+(0,106 *$ AGM $)$

Theo đó, mức độ ảnh hưởng của các biến độc lập đến sự hài lòng của du khách nội địa sau đợt 1 đại dịch COVID-19 theo thứ tự là An toàn điểm đến, Tài nguyên du lịch và điều kiện vật chất, Môi trường, Cơ sở lưu trú và cuối cùng là Dịch vụ ăn uống, giải trí, mua sắm.

05 biến độc lập còn lại trong phân tích hồi quy bội lần 2 có Sig.<0,5 đồng nghĩa với các giả thuyết $\mathrm{H} 1, \mathrm{H} 2$, $\mathrm{H} 4, \mathrm{H} 5$ và $\mathrm{H} 6$ được chấp nhận, giả thuyết $\mathrm{H} 3$ bị bác bỏ.

Mặt khác, với giá trị $\mathrm{VIF}<2$ và hệ số Durbin Waston $(\mathrm{d})=1,906$ nằm trong khoảng $\mathrm{dL}<\mathrm{d}<4-\mathrm{dU}$ là $1,811<1,906<2,139$ (với kích thước mẫu $\mathrm{n}=393$, tham số $\mathrm{k}$ ' $=5$, tra bảng Durbin - Waston có $\mathrm{dL}=1,811$ và $\mathrm{dU}=1,861$ ) thì mô hình không có hiện tượng đa cộng tuyến và hiện tượng tự tương quan. Thêm nữa, trong kiểm định Spearman, phần dư chuẩn hóa của các biến đều có giá trị Sig.> 0,05 nên mô hình cũng không có hiện tượng phương sai phần dư thay đổi.

Thực hiện kiểm định đối với 04 biến kiểm soát, được kết quả là không có sự khác nhau về mức độ hài lòng của từng nhóm du khách nội địa theo tiêu chí giới tính, độ tuổi, trình độ học vấn và số lần đến du lịch TP.HCM. Vì vậy, các hàm ý được đưa ra trong phần sau sẽ mang tính phổ quát cho toàn bộ du khách nội địa khi đến TP.HCM

\subsection{Thảo luận kết quả nghiên cứu}

Ảnh hưởng của từng yếu tố độc lập được thể hiện trong bảng sau:

Bảng 8 . Mức độ ảnh hưởng và giá trị trung bình của các yếu tố độc lập

\begin{tabular}{|l|l|l|l|l|}
\hline STT & Yếu tố độc lập & Hệ số Beta & Tỷ lệ (\%) & Giá trị trung bình \\
\hline 1 & An toàn điểm đến & 0,605 & 54,65 & 4,1877 \\
\hline 2 & Tài nguyên du lịch và điều kiện vật chất & 0,142 & 12,83 & 4,1405 \\
\hline 3 & Môi trường & 0,129 & 11,65 & 4,2176 \\
\hline 4 & Cơ sở lưu trú & 0,125 & 11,29 & 1,8448 \\
\hline 5 & Dịch vụ ăn uống, giải trí, mua sắm & 0,106 & 9,58 & 4,1476 \\
\hline & Tổng cộng & - & 100,00 & - \\
\hline
\end{tabular}

Nguồn: Tổng hợp kết quả nghiên cưu

Kết quả nghiên cứu cho thấy, yếu tố có ảnh hưởng mạnh nhất đến Sự hài lòng của du khách nội địa là An toàn điểm đến với hệ số Beta=0,605 chiếm $54,65 \%$ - nhiều hơn so với 04 yếu tố kia cộng lại. Đây là điều khác biệt so với các nghiên cứu cùng loại trước đây, cả ở trong và ngoài nước. Nguyên nhân dễ hiểu là vì 
COVID-19 mà du khách quan tâm hơn đến An toàn của điểm đến. Du khách sẽ hài lòng một khi sức khỏe và tính mạng của họ được an toàn, nhất là an toàn COVID. Chính vì vậy, điểm đến TP.HCM nói chung, các công ty du lịch nói riêng cần chú ý hơn nữa yếu tố này để sao cho trong mùa dịch, du khách vẫn được an toàn mà du lịch vẫn được phát triển. Trước năm 2019, yếu tố An toàn điểm đến được đo lường bằng các biến truyền thống. Bởi vậy, trong nghiên cứu của Shahrivar (2012) yếu tố này chỉ ảnh hưởng mạnh thứ ba đến sự hài lòng du khách.

Yếu tố Tài nguyên du lịch và điều kiện vật chất trong nghiên cứu này mạnh thứ hai; yếu tố cơ sở lưu trú mạnh thứ tư; yếu tố ăn uống, giải trí và mua sắm mạnh thứ năm. Vậy nhưng trong nghiên cứu của Võ Thị Cẩm Nga (2014) tương ứng là mạnh thứ nhất, thứ hai và thứ ba. Trong khi đó, yếu tố môi trường của nghiên cứu này mạnh thứ ba còn trong nghiên cứu của Tribe và Snaith (1998) lại mạnh thứ tư.

Nguyên nhân của sự khác nhau nói trên là do bối cảnh nghiên cứu không giống nhau. Chính nghiên cứu trong bối cảnh có dịch nên An toàn đã là yếu tố quyết định mức độ hài lòng của du khách nội địa đối với điểm đến TP.HCM.

\section{MỘT SỐ KHUYẾN NGH!}

\section{1. Đối với yếu tố An toàn điểm đến}

Đây là yếu tố ảnh hưởng mạnh nhất đến sự hài lòng của du khách nội địa sau đợt một đại dịch COVID-19 với hệ số beta bằng 0,605 . Hơn nữa, điểm trung bình là 4,19 chứng tỏ du khách hài lòng với yếu tố này. Tuy vậy, trong khi đại dịch COVID-19 vẫn chưa được kiểm soát hoàn toàn thì điểm đến TP.HCM cần yêu cầu các doanh nghiệp kinh doanh du lịch trên địa bàn tuân thủ nghiêm ngặt các văn bản quy định, các hướng dẫn có liên quan đến việc phòng chống COVID-19, đồng thời thường xuyên tuyên truyền, nâng cao ý thức của khách du lịch và cả người dân trong việc phòng chổng lây lan của dịch bệnh. Mọi lúc, mọi nơi trong hành trình du lịch, công ty phải luôn có nước sát khuẩn, khẩu trang y tế, thường xuyên chú ý đến tình trạng sức khỏe của du khách. Trước và sau một cuộc hành trình cần phải vệ sinh, tẩy trùng phương tiện vận chuyển, thường xuyên phun thuốc khử trùng các điểm mà du khách đến vui chơi, giải trí và nghỉ dưỡng.

Ngoài ra, TP.HCM cần quan tâm hơn nữa đến việc giải quyết các tệ nạn: ăn xin, chèo kéo, đeo bám, năn nỉ để bán hàng và bán vé số; có biện pháp mạnh để không còn tình trạng cướp giật, lừa đảo du khách; xử lý nghiêm và kịp thời các trường hợp du khách bị xâm hại tài sản, sức khỏe và tính mạng.

\section{2. Đối với yếu tố Tài nguyên du lịch và điều kiện vật chất}

Đây là yếu tố ảnh hưởng mạnh thứ hai đến sự hài lòng của du khách với hệ số beta bằng 0,142 . Ngoài ra, điểm trung bình là 4,14 cũng cho thấy, du khách đồng ý với yếu tố Tài nguyên du lịch và điều kiện vật chất của điểm đến TP.HCM. Tuy vậy, chính quyền TP.HCM cần lưu ý ba vấn đề sau:

Thư nhất, cần nâng cấp, phân luồng hoặc xây dựng mới một số trục giao thông, đảm bảo cho việc đi lại của du khách được tiện lợi, an toàn và nhanh chóng hơn

Thư hai, rất cần có các trạm ATM để đổi ngoại tệ ra đồng tiền nội địa. Hiện nay, các nước trong khu vực ASEAN đã thực hiện dịch vụ này bằng ATM, thay vì chỉ có tại ngân hàng thương mại như ở nước ta.

Thư $b a$, thường xuyên tìm kiếm, sưu tầm và mua lại những hiện vật có giá trị lịch sử, văn hóa để trưng bày cho du khách thưởng ngoạn, qua đó, tạo điều kiện để họ quay lại.

Thư tux, cần khuyếch trương các giá trị riêng có của điểm du lịch thông qua phát triển tập hợp các điểm thu hút du khách theo quần thể nhằm tạo thuận lợi cho du khách khi đi thưởng ngoạn.

\section{3. Đối với yếu tố Môi trường}

Đây là yếu tố ảnh hưởng mạnh thứ ba đến sự hài lòng của du khách nội địa với hệ số beta bằng 0,129 và với điểm trung bình là 4,22 đã cho thấy, du khách đồng ý với yếu tố Môi trường du lịch của TP.HCM. Tuy nhiên để tăng sự hài lòng của du khách, TP.HCM cần khai thác, sử dụng các nguồn tài nguyên du lịch một cách hợp lý, giảm thiểu chất thải ra môi trường bằng cách khuyến khích bán và sử dụng hàng hóa có bao bì tự hủy; mặt khác để tạo công ăn việc làm, thành phố cần quy hoạch một số khu vực nhất định cho phép người bán hàng rong được hành nghề. Các cơ sở vệ sinh công cộng trong thành phố nói chung và tại các điểm du lịch nói riêng cần được xây dựng nhiều hơn, còn các cơ sở hiện có phải sạch sẽ và thông thoáng hơn nữa. Hạn chế, đi đến cấm triệt để tình trạng công nhân vệ sinh đường phố làm việc trong giờ hành chính gây cản trở giao thông và ô nhiễm môi trường. 


\section{4. Đối với yếu tố Cơ sở lưu trú}

Đây là yếu tố ảnh hưởng mạnh thứ tư đến sự hài lòng của du khách nội địa khi có hệ số beta bằng 0,126 . Thế nhưng, từ cỡ mẫu 393, tính ra điểm trung bình của yếu tố chỉ được 1,84 . Điều này cho thấy, du khách không đồng ý với yếu tố Cơ sở lưu trú của TP.HCM. Do vậy, TP.HCM cần:

- Phối hợp với cơ quan liên quan thường xuyên kiểm tra các cơ sở lưu trú trong việc cung cấp dịch vụ theo tiêu chuẩn "Sao", tránh tình trạng sao lớn mà chất lượng dịch vụ lại thấp, trong khi giá phòng lại không tương xứng.

- Cần tạo điều kiện hơn cho các doanh nghiệp đầu tư xây dựng thêm các cơ sở lưu trú du lịch cao cấp mang tầm cỡ quốc tế

- Phối hợp với các trường đào tạo và công ty du lịch để cung cấp những chương trình đào tạo nhân lực tốt, giúp nâng cao chất lượng của đội ngũ nhân viên cả về nghiệp vụ và đạo đức, tác phong.

\section{5. Đối với yếu tố Dịch vụ ăn uống, giải trí và mua sắm}

Đây là yếu tố ảnh hưởng yếu nhất đến sự hài lòng của du khách vì hệ số beta nhỏ nhất, bằng 0,106 . Tuy vậy, du khách đến TP.HCM nhìn chung là hài lòng với yếu tố này vì có điểm trung bình là 4,1476 . Xét thấy, muốn tăng cường sự hài lòng của du khách, TP.HCM cần hoàn chỉnh hệ thống tiêu chuẩn chất lượng, vệ sinh cho các nhà hàng, quán ăn và thường xuyên phối hợp với các đơn vị liên quan kiểm tra chất lượng, vệ sinh của những cơ sở này. Song song đó, thành phố cần có chế tài quản lý chặt chẽ các cơ sở kinh doanh hoạt động vui chơi giải trí về đêm, tạo điều kiện cho các cơ sở kinh doanh dịch vụ ăn uống, giải trí, mua sắm hoạt động một cách thuận lợi. Thành phố cũng cần học hỏi kinh nghiệm của các địa phương ở trong và cả ngoài nước để phát triển hơn nữa du lịch về "đêm" trên địa bàn. Qua đó, có điều kiện để tăng số lượng công ăn việc làm và tổng thu của ngành "công nghiệp không khói" này.

\section{KẾT LUÂN VÀ HƯớNG NGHIÊN CÚU TIẾP THEO}

Thông qua phương pháp định tính và định lượng, nghiên cứu đã tìm ra 05 yếu tố thực sự có ảnh hưởng đến sự hài lòng của du khách nội địa sau đợt một đại dịch COVID-19. Đó là An toàn điểm đến, Tài nguyên du lịch và điều kiện vật chất, Môi trường, Cơ sở lưu trú và cuối cùng là Dịch vụ ăn uống, giải trí, mua sắm. Trong 05 yếu tố trên, thì yếu tố An toàn điểm đến có ảnh hưởng mạnh nhất, chiếm hơn một nửa tổng ảnh hưởng. 04 yếu tố còn lại có mức độ ảnh hưởng không lớn, dao động từ 0,106 đến 0,142 . Điều đó chứng tỏ - muốn phát triển du lịch của điểm đến TP.HCM (và có lẽ cho tất cả các địa phương của cả nước) trong giai đoạn hiện nay, trước tiên phải đảm bảo an toàn, đặc biệt là an toàn COVID-19 cho du khách. Trên cơ sở kết quả nghiên cứu, 05 khuyến nghị đã được nhóm tác giả đề xuất. Hy vọng rằng, nếu thực hiện được những khuyến nghị này, du lịch của điểm đến TP.HCM vẫn sẽ phát triển và phát triển bền vững ngay cả khi COVID-19 vẫn chưa được kiểm soát hoàn toàn.

Nghiên cứu này được thực hiện trong điều kiện có dịch, vì vậy mẫu được khảo sát hoàn toàn bằng trực tuyến với cỡ mẫu chưa lớn là 393. Mặt khác, 05 yếu tố độc lập còn lại sau phân tích chỉ ảnh hưởng đến sự hài lòng của du khách nội địa được 56,8\%. Vì vậy, hướng nghiên cứu tiếp theo nên tăng kích thước mẫu và đưa thêm vào mô hình nghiên cứu một số yếu tố độc lập để tăng độ phù hợp của mô hình và tính khả thi của các khuyến nghị đối với điểm đến TP.HCM.

\section{TÀI LIỆU THAM KHẢO}

\section{Tiếng Việt}

[1] Luật Du lịch (2017)

[2] Luật Di sản Văn hóa (2001)

[3] Nguyễn Văn Đính, Trần Thị Minh Hòa (2006). Giáo trình Kinh tế du lịch. NXB Lao động.

[4] Hoàng Trọng và Chu Nguyễn Mộng Ngọc (2008). Phân tích dĩu liệu nghiên cứu SPSS. NXB Thống kê.

[5] Nguyễn Đức Minh (2008). Giáo trình Tổng quan về du lịch. NXB Thống kê

[6] Lê Thông, Nguyễn Minh Tuệ, Lê Mỹ Dung, Trần Ngọc Điệp, Nguyễn Trọng Đức, Vũ Đình Hòa, Lê Văn Tin (2010). Địa lí du lịch Việt Nam. NXB Giáo dục Việt Nam. 
[7] Nguyễn Hồng Giang, Lưu Thanh Đức Hải (2011).Phân tích các nhân tố ảnh hưởng đến sụ hài lòng của du khách khi đến du lịch ở Kiên Giang. Tạp chí khoa học Trường Đại học Cần Thơ, 19b, 85-96

[8] Nguyễn Đình Thọ (2013). Phuoong pháp nghiên cưu khoa học trong kinh doanh. NXB Lao động - Xã hội.

[9] Võ Thị Cẩm Nga (2014). Nhân tố ảnh hưởng đến sụ hài lòng của khách du lịch nội đối với du lịch văn hóa Thành phố Cần Thơ. Luận văn Thạc sĩ, Trường Đại học Đà Nẵng.

[10] Đặng Thị Thanh Loan (2015). Các yếu tổ ảnh huởng đến sụ hài lòng của khách du lịch đối với điểm đến Bình Định. Tạp chí Phát triển kinh tế, 26(9), 101-119.

[11] Trần Đức Thanh (2017). Giáo trình Nhập môn khoa học Du lịch. NXB Đại học Quốc gia.

[12] Đinh Kiệm và Nguyễn Đình Bình (2019). Úng dụng mô hình HOLSAT đánh giá sụ hài lòng của khách du lịch nội địa tại điểm đến thành phố Bảo Lộc. Tạp chí Công Thương.

\section{TIẾNG ANH}

[1] Bachelet, D. (1992). Measuring Satisfaction or the Chain, the Tree and the Nest. In ESOMAR marketing research congress (pp. 229-229). ESOMAR.

[2] Dumont, E., Asensio, M., \& Mortari, M. (2010). 10 Image, Construction and Representation in Tourism Promotion and Heritage Management. Tourism and Visual Culture: Theories and Concepts, 1, 124.

[3] Gang Li (2019). EHL's 3rd Annual Hospitality Finance \& Economics Research Conference, UK.

[4] Jayasinghe, M.K.D, Gnanapala, W.K.A.C, \& Sandaruwani, J.A.R.C. (2015), Factors affecting tourists' perception and satisfaction in Nuwara Eliya, Sri Lanka, Journal of Economic Policy, 2, 1-15.

[5] Kotler, P. (2001). Direction to marketing. Pearson Education.

[6] Kozak, M. (2001). Repeaters' behavior at two distinct destinations. Annals of tourism research, 28(3), 784-807.

[7] Lee, E. J. (2005). Creating value for online shoppers: Implications for satisfaction and loyalty. ACR Asia-Pacific Advances

[8] Oliver, R. L. (2000). Customer satisfaction with service. Handbook of services marketing and management, 247254.

[9] Oliver, R. L. (1980). A cognitive model of the antecedents and consequences of satisfaction decisions. Journal of marketing research, 17(4), 460-469.

[10] Parasuraman, A., Berry, L. L., \& Zeithaml, V. A. (1991). Refinement and reassessment of the SERVQUAL scale. Journal of retailing, 67(4), 420-450.

[11] Pizam, A. (1978). Tourism's impacts: The social costs to the destination community as perceived by its residents. Journal of travel research, 16(4), 8-12.

[12] Pizam, A., Neumann, Y., \& Reichel, A. (1978). Dimentions of tourist satisfaction with a destination area. Annals of tourism Research, 5(3), 314-322.

[13] Shahrivar, R.B (2012), Factors that influence tourist satisfaction, Journal of Travel and Tourism Research, Special Issue, 61-79.

[14] Tribe, J., \& Snaith, T. (1998). From SERVQUAL to HOLSAT: holiday satisfaction in Varadero, Cuba. Tourism management, 19(1), 25-34.

[15] Wilson, A., Zeithaml, V. A., Bitner, M. J., \& Gremler, D. D. (2012). Services marketing: Integrating customer focus across the firm. 2nd European Edition ed: UK.

Ngày nhận bài: 10/05/2021

Ngày chấp nhận đăng: 08/06/2021 
Phụ lục:

Bảng 1. Biến quan sát, cách mã hóa và nguồn kế thừa

\begin{tabular}{|c|c|c|c|}
\hline STT & Các yếu tố và biến quan sát & Mã hóa & Nguồn \\
\hline $\mathbf{I}$ & Tài nguyên du lịch và điều kiện vật chất & TNDK & $\begin{array}{c}\text { Võ Thị Cẩm Nga (2014); Tribe và } \\
\text { Snaith (1998) }\end{array}$ \\
\hline 1 & Nhiều điểm tham quan du lịch hấp dẫn & TNDK1 & // \\
\hline 2 & Nhiều điểm tham quan có giá trị lịch sử, văn hóa & TNDK2 & $/ /$ \\
\hline 3 & Các dịch vụ (ngân hàng, y tế, viễn thông...) sẵn có & TNDK3 & // \\
\hline 4 & Hệ thống đường giao thông thuận lợi & TNDK4 & // \\
\hline 5 & Gần sân bay & TNDK5 & // \\
\hline II & Môi trường & MT & $\begin{array}{l}\text { Võ Thị Cẩm Nga (2014); Đinh } \\
\text { Kiệm và Nguyễn Đình Bình } \\
\text { (2019); Tribe và Snaith (1998); } \\
\text { Bindu Narayan (2008) }\end{array}$ \\
\hline 1 & Thời tiết dễ chịu & MT1 & $/ /$ \\
\hline 2 & Người dân thân thiện, mến khách & MT2 & // \\
\hline 3 & Vệ sinh tại điểm tham quan tốt & MT3 & // \\
\hline 4 & Ít người bán hàng rong & MT4 & // \\
\hline 5 & Điểm đến du lịch không bị ô nhiễm & MT5 & // \\
\hline III & Di sản văn hóa & DSVH & $\begin{array}{l}\text { Tribe và Snaith (1998), Shahrivar } \\
\text { (2012), Jayasinghe, Gnanapala và } \\
\text { Sandaruwani (2015), Võ Thị Cẩm } \\
\text { Nga (2014), Đặng Thị Thanh } \\
\text { Loan (2015), Đinh Kiệm - } \\
\text { Nguyễn Đình Bình (2019) }\end{array}$ \\
\hline 1 & Điểm đến TP.HCM có nhiều công trình, kiến trúc & DSVH1 & $/ /$ \\
\hline 2 & Điểm đến TP.HCM có nhiều bảo tàng & DSVH2 & // \\
\hline 3 & Các điểm tham quan thuận tiện đi lại & DSVH3 & // \\
\hline 4 & Vé tham quan khu du lịch phù hợp & DSVH4 & // \\
\hline IV & Cơ sở lưu trú & CSLT & $\begin{array}{l}\text { Tribe và Snaith (1998); Võ Thị } \\
\text { Cẩm Nga (2014) }\end{array}$ \\
\hline 1 & Có nhiều cơ sở lưu trú cấp hạng cao & CSLT1 & $/ /$ \\
\hline 2 & Các dịch vụ trong cơ sở lưu trú đảm bảo chất lượng & CSLT2 & // \\
\hline 3 & Các dịch vụ trong cơ sở lưu trú đa dạng & CSLT3 & // \\
\hline 4 & Mức giá được niêm yết & CSLT4 & // \\
\hline 5 & Nhân viên chuyên nghiệp, thân thiện & CSLT5 & // \\
\hline $\mathrm{V}$ & Dịch vụ ăn uống, giải trí, mua sắm & AGM & $\begin{array}{l}\text { Võ Thị Cẩm Nga (2014); Tribe và } \\
\text { Snaith (1998) }\end{array}$ \\
\hline 1 & Có thể thưởng thức đặc sản địa phương & AGM1 & $/ /$ \\
\hline 2 & Các nhà hàng có đồ ăn, thức uống chất lượng, hợp vệ sinh & AGM2 & // \\
\hline 3 & Có nhiều cơ sở phục vụ ăn uống, giải trí, mua sắm & AGM3 & // \\
\hline 4 & Nhiều các hoạt động vui chơi, giải trí về đêm & AGM4 & // \\
\hline VI & An toàn điểm đến & ATDD & $\begin{array}{l}\text { Bindu Narayan (2008) } \\
\text { Shahrivar (2012) }\end{array}$ \\
\hline 1 & Không có nạn ăn xin, cướp giật và đeo bám du khách & ATDD1 & // \\
\hline
\end{tabular}



ĐIỂM ĐẾN THÀNH PHỐ HỒ CHÍ MINH SAU ĐỢT MỘT ĐẠI DỊCH COVID-19

\begin{tabular}{|c|c|c|c|}
\hline 2 & An toàn về tài sản và tính mạng của du khách & ATDD2 & /I \\
\hline 3 & $\begin{array}{l}\text { Điểm đến TP.HCM luôn lưu ý du khách về đề phòng } \\
\text { COVID - } 19\end{array}$ & ATDD3 & Đề xuất \\
\hline \multirow[t]{2}{*}{4} & $\begin{array}{l}\text { Điểm đến TP.HCM có các phương tiện phòng chống } \\
\text { COVID - } 19 \text { cho du khách }\end{array}$ & ATDD4 & Đề xuất \\
\hline & Sự hài lòng điểm đến & SHL & $\begin{array}{l}\text { Bindu Narayan (2008) } \\
\quad \text { Gang Li (2019) }\end{array}$ \\
\hline 1 & Tôi hài lòng với điểm đến TP.HCM & SHL1 & // \\
\hline 2 & Lần sau tôi vẫn chọn điểm đến TP.HCM để đi du lịch & SHL2 & // \\
\hline 3 & $\begin{array}{l}\text { Tôi sẵn lòng giới thiệu người thân đi du lịch tại điểm đến } \\
\text { TP.HCM }\end{array}$ & SHL3 & // \\
\hline
\end{tabular}

Nguồn: Tổng hợp và đề xuất

Bảng 2. Kết quả kiểm định Cronbach's Alpha (N=393)

\begin{tabular}{|c|c|c|c|}
\hline Biến & Tương quan biến tổng & Cronbach's Alpha nếu loại biến & Cronbach's Alpha \\
\hline \multicolumn{4}{|c|}{ I. Tài nguyên du lịch và điều kiện vật chất } \\
\hline TNDK1 & ,565 & ,766 & \multirow{5}{*}{0,799} \\
\hline TNDK2 & ,568 & ,765 & \\
\hline TNDK3 & ,654 & ,740 & \\
\hline TNDK4 & ,563 & ,766 & \\
\hline TNDK5 & ,563 & ,767 & \\
\hline \multicolumn{4}{|c|}{ II. Môi trường } \\
\hline MT1 & ,491 & ,688 & \multirow{4}{*}{0,730} \\
\hline MT2 & ,544 & ,656 & \\
\hline MT3 & ,509 & 677 & \\
\hline MT4 & ,544 & ,657 & \\
\hline \multicolumn{4}{|c|}{ III. Di sản văn hóa } \\
\hline DSVH1 & ,623 & ,740 & \multirow{4}{*}{0,797} \\
\hline DSVH2 & 639 & ,733 & \\
\hline DSVH3 & ,653 & ,725 & \\
\hline DSVH4 &, 528 &, 789 & \\
\hline \multicolumn{4}{|c|}{ IV. Co sở lưu trú } \\
\hline CSLT1 & ,727 & ,842 & \multirow{5}{*}{0,874} \\
\hline CSLT2 & ,597 & 871 & \\
\hline CSLT3 &, 559 &, 880 & \\
\hline CSLT4 & ,810 & 819 & \\
\hline CSLT5 & 828 &, 814 & \\
\hline \multicolumn{4}{|c|}{ V. Dịch vụ ăn uống, giải trí, mua sắm } \\
\hline AGM2 & ,568 & ,665 & \multirow{3}{*}{0,745} \\
\hline AGM3 & ,647 &, 572 & \\
\hline AGM4 & ,504 & ,736 & \\
\hline
\end{tabular}



ĐIỂM ĐẾN THÀNH PHỐ HỒ CHÍ MINH SAU ĐỢT MỘT ĐẠI DỊCH COVID-19

\begin{tabular}{|c|c|c|c|}
\hline \multicolumn{4}{|c|}{ VI. An toàn điểm đến } \\
\hline ATDD1 & ,621 &, 744 & \multirow{4}{*}{0,799} \\
\hline ATDD2 & ,625 &, 743 & \\
\hline ATDD3 & ,665 &, 722 & \\
\hline ATDD4 &, 542 & ,785 & \\
\hline \multicolumn{4}{|c|}{ Sụ̂ hài lòng } \\
\hline SHL1 & ,692 &, 804 & \multirow{3}{*}{0,845} \\
\hline SHL2 &, 751 &, 747 & \\
\hline SHL3 & ,698 & ,802 & \\
\hline
\end{tabular}

Nguồn: Kết quả phân tích SPSS

Bảng 3. Kết quả phân tích EFA cho các yếu tố độc lập

\begin{tabular}{|c|c|c|c|c|c|c|c|c|}
\hline \multirow[t]{2}{*}{ Yếu tố } & & \multicolumn{6}{|c|}{ Hệ số tải nhân tố } & \multirow{2}{*}{$\begin{array}{c}\text { Cronbach's } \\
\text { Alpha }\end{array}$} \\
\hline & & 1 & 2 & 3 & 4 & 5 & 6 & \\
\hline \multirow{5}{*}{ Cơ sở lưu trú } & CSLT5 & ,871 & & & & & & \multirow{5}{*}{0,874} \\
\hline & CSLT4 & ,868 & & & & & & \\
\hline & CSLT1 & ,725 & & & & & & \\
\hline & CSLT2 & ,517 & & & & & & \\
\hline & CSLT3 &, 500 & & & & & & \\
\hline \multirow{4}{*}{ An toàn điểm đến } & ATDD3 & & ,772 & & & & & \multirow{4}{*}{0,799} \\
\hline & ATDD1 & & ,730 & & & & & \\
\hline & ATDD2 & & ,666 & & & & & \\
\hline & ATDD4 & & ,647 & & & & & \\
\hline \multirow{5}{*}{$\begin{array}{l}\text { Tài nguyên du lịch và } \\
\text { điều kiện vật chất }\end{array}$} & TNDK3 & & & ,720 & & & & \multirow{5}{*}{0,799} \\
\hline & TNDK2 & & & ,706 & & & & \\
\hline & TNDK1 & & & ,700 & & & & \\
\hline & TNDK5 & & & 675 & & & & \\
\hline & TNDK4 & & & ,638 & & & & \\
\hline \multirow{4}{*}{ Di sản văn hóa } & DSVH3 & & & & ,810 & & & \multirow{4}{*}{0,797} \\
\hline & DSVH2 & & & & ,797 & & & \\
\hline & DSVH1 & & & & ,787 & & & \\
\hline & DSVH4 & & & & ,700 & & & \\
\hline \multirow{4}{*}{ Môi trường } & MT2 & & & & & ,767 & & \multirow{4}{*}{0,730} \\
\hline & MT3 & & & & & 645 & & \\
\hline & MT4 & & & & & ,584 & & \\
\hline & MT1 & & & & & ,532 & & \\
\hline \multirow{3}{*}{$\begin{array}{c}\text { Dịch vụ ăn uống, giải } \\
\text { trí, mua sắm }\end{array}$} & AGM3 & & & & & &, 772 & \multirow{3}{*}{0,745} \\
\hline & AGM2 & & & & & & ,768 & \\
\hline & AGM4 & & & & & & ,509 & \\
\hline Tổng & \multicolumn{8}{|c|}{$63,192 \%$} \\
\hline \multicolumn{2}{|c|}{ Giá trị KMO = 0,870 } & \multicolumn{7}{|c|}{ Bartlett's test Sig. $=\mathbf{0 , 0 0 0}$} \\
\hline
\end{tabular}


CÁC YÊU TÔ ẢNH HƯỞNG ĐÊN SỰ HÀI LÒNG CỦA DU KHÁCH NỘI ĐỊA ĐỐI VỚI ĐIỂM ĐẾN THÀNH PHỐ HỒ CHÍ MINH SAU ĐỢT MỘT ĐẠI DỊCH COVID-19

Bảng 4. Kết quả phân tích EFA cho yếu tố phụ thuộc

\begin{tabular}{|c|c|c|}
\hline \multirow{2}{*}{ STT } & \multirow{2}{*}{ Biến quan sát } & Hệ số tải nhân tố \\
\cline { 2 - 3 } & SHL2 & 1 \\
\hline 1 & SHL3 &, 896 \\
\hline 2 & SHL1 &, 866 \\
\hline $3 \quad$ &, 863 \\
\hline \multicolumn{2}{|c|}{ Cronbach's Alpha } & $\mathbf{0 , 8 4 5}$ \\
\hline \multicolumn{2}{|c|}{ Sig. } & $\mathbf{0 , 0 0 0}$ \\
\hline \multicolumn{2}{|c|}{ KMO } & $\mathbf{0 , 7 2 3}$ \\
\hline \multicolumn{2}{|c|}{ Phương sai trích (\%) } \\
\end{tabular}

Nguồn: Kết quả phân tích SPSS

Bảng 6. Kết quả phân tích hồi quy lần 1

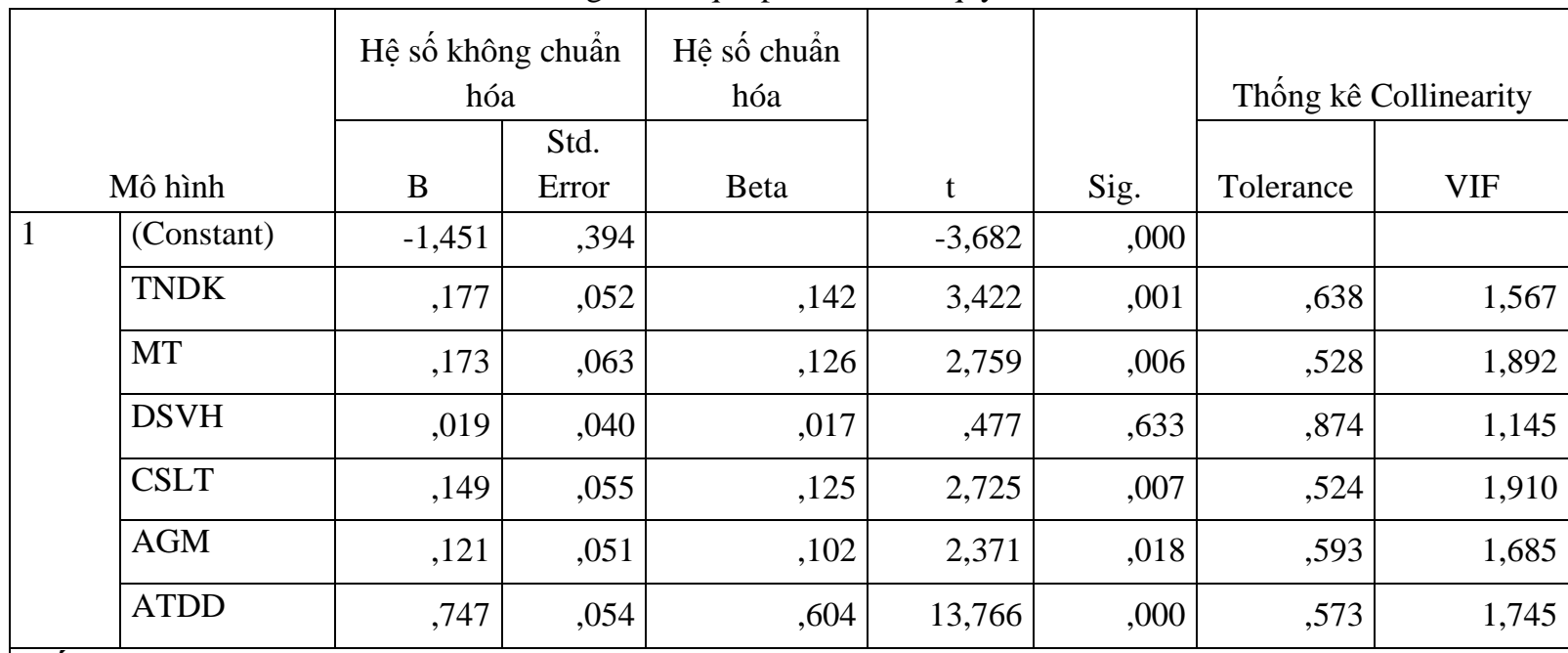

Biến phụ thuộc: Sự hài lòng

\begin{tabular}{|c|c|c|}
\hline $\mathrm{R}=0,758$ & $\mathrm{R}^{2}=0,575$ & $\mathrm{R}^{2}$ hiệu chỉnh $=0,568$ \\
\hline Durbin-Watson $=1,908$ & $\mathrm{~F}=86,900$ & Sig. $=0,000$ \\
\hline
\end{tabular}

Nguồn: Kết quả phân tích SPSS 